\title{
Task Force Report 6. Report on Financing the New Model of Family Medicine
}

\author{
Stephen J. Spann, MD, MBA, \\ for the members of Task Force 6 \\ and the Executive Editorial Team* \\ Chair, Task Force 6, Houston, Tex. \\ *See Acknowledgments for a complete list \\ of Task Force 6 members and the Executive \\ Editorial Team.
}

\begin{abstract}
PURPOSE To foster redesigning the work and workplaces of family physicians, this Future of Family Medicine task force was created to formulate and recommend a financial model that sustains and promotes a thriving New Model of care by focusing on practice reimbursement and health care finances. The goals of the task force were to develop a financial model that assesses the impact of the New Model on practice finances, and to recommend health care financial policies that, if implemented, would be expected to promote the New Model and the primary medical care function in the United States for the next few decades.
\end{abstract}

METHODS The members of the task force reflected a wide range of professional backgrounds and expertise. The group met in person on 2 occasions and communicated by e-mail and conference calls to achieve consensus. A marketing study was carried out using focus groups to test the concept of the New Model with consumers. External consultants with expertise in health economics, health care finance, health policy, and practice management were engaged to assist the task force with developing the microeconomic (practice level) and macroeconomic (societal level) financial models necessary to achieve its goals. Model assumptions were derived from the published medical literature, existing practice management databases, and discussions with experienced physicians and other content experts. The results of the financial modeling exercise are included in this report. The initial draft report of the findings and recommendations was shared with a reactor panel representing a broad spectrum of constituencies. Feedback from these individuals was reviewed and incorporated, as appropriate, into the final report.

RESULTS The practice-level financial model suggests that full implementation of the New Model of care within the current fee-for-service system of reimbursement would result in a $26 \%$ increase in compensation (from $\$ 167,457$ to $\$ 210,288$ total annual compensation) for prototypical family physicians who maintain their current number of work hours. Alternatively, physicians could choose to decrease their work hours by $12 \%$ and maintain their current compensation. This result is sensitive to physician practice group size. The societal level financial model shows that modifications in the current reimbursement system could lead to further improvements in compensation for family physicians practicing the New Model of care. Reimbursement for e-visits and chronic disease management could further increase total annual compensation to $\$ 229,849$ for prototypical family physicians maintaining their current number of work hours. The widespread introduction of quality-based physician incentive bonus payments similar to some current programs that have been implemented on a limited basis could further increase total annual compensation up to $\$ 254,500$. The adoption of a mixed reimbursement model, which would add an annual per-patient fee, a chronic care bonus, and an overall performance bonus to the current reimbursement system, could increase total annual compensation for the prototypical family physician continuing the current number of hours worked to as much as $\$ 277,800$, a $66 \%$ increase above current compensation levels. The cost of transition to the New Model is estimated to range from $\$ 23,442$ to $\$ 90,650$ per physician, depending on the assumed magnitude of productivity loss associated with implementing an electronic health record. The financial impact of enhanced use of primary care on the costs of health care in the United States was estimated. If every American used a primary care physician as their usual source of care, health care costs would likely decrease by $5.6 \%$, resulting in national savings of $\$ 67$ billion dollars per year, with an improvement in the quality of the health care provided. 
CONCLUSIONS Family physicians could use New Model efficiency to increase compensation or to reduce work time. There are alternative reimbursement methodologies compatible with the New Model that would allow family physicians to share in the health care cost savings achieved as a result of effective and efficient delivery of care. The New Model of care should enhance health care while propelling the US system toward improved performance and results that are satisfying to patients, health care professionals, purchasers, and payers. The New Model needs to be implemented now. Given the recognized need for improvements in the US health care system in the areas of quality, safety, access and costs, there is no reason to delay.

Ann Fam Med 2004;S1-S21. DOI: 10.1370/afm.237.

TASK FORCE CHARGE: Formulate and recommend a financial model that sustains and promotes a thriving New Model of family medicine practice by focusing on practice reimbursement and health care finances.

\section{PREFACE}

T The leadership of 7 national family medicine organizations initiated the Future of Family Medicine (FFM) project in 2002 in response to growing frustration among family physicians, confusion among the public about the role of family physicians, and continuing inequities and inefficiencies in the US health care system. ${ }^{1}$ The goal of the project was to transform and renew the specialty of family medicine to meet the needs of individuals and society in a changing environment. Five task forces were named and given the following charges:

- Task Force 1: Consider the core attributes and values of family medicine and propose ideas about reforming family medicine and primary care to meet the contemporary needs and expectations of the people of the United States

- Task Force 2: Determine the training needed for family physicians to deliver core attributes and system services

- Task Force 3: Ensure that family physicians deliver core attributes and system services throughout their careers

- Task Force 4: Determine strategies for communicating the role of family physicians within medicine and health care, as well as to purchasers and consumers

- Task Force 5: Determine family medicine's leadership role in shaping the future health care delivery system

The reports and recommendations of these task forces were reviewed and synthesized by the Project
Leadership Committee, which published its summary findings and recommendations in March 2004, along with the reports of each of the 5 task forces. (FFM Final Report $^{1}$ and task force reports $\left.{ }^{2-6}\right)$. The FFM project received financial support from the 7 family medicine organizations and from a combination of other supporters listed at the end of this report. The American Academy of Family Physicians provided implementation oversight for Task Force 6 through funding and staff support. Progress on all FFM projects has been reported to the Family Medicine Working Party, which includes representation of the previously mentioned 7 family medicine organizations.

The FFM Report included 10 recommendations, one of which was to develop a New Model of family medicine. ${ }^{1}$ The recommendation from the FFM Report reads:

Family medicine will redesign the work and workplaces of family physicians. This redesign will foster a New Model of care based on the concept of a relationship-centered personal medical bome, which serves as the focal point through which all individuals - regardless of age, gender, race, ethnicity, or socioeconomic status participate in health care. In this new medical home, patients receive a basket of acute, chronic, and preventive medical care services that are accessible, accountable, comprehensive, integrated, patient-centered, safe, scientifically valid, and satisfying to both patients and their physicians. This New Model will include technologies that enhance diagnosis and treatment for a large portion of problems that patients bring to their family physicians. Business plans and reimbursement models will be developed to enable the reengineered practices of family physicians to thrive as personal medical homes, and resources will be developed to help patients make informed decisions about choosing a personal medical home. A financially self-sustaining national resource will be implemented to provide practices with ongoing support in the transition to the New Model of family medicine.

The major characteristics of the New Model of family medicine include:

- Personal medical home

- Patient-centered care

- Team approach to care

- Elimination of barriers to access

- Advanced information systems, including a standardized electronic health record (EHR)

- Redesigned, more functional offices

- Whole-person orientation

- Care provided in a community context 
- Focus on quality and safety

- Enhanced practice finance

- Defined basket of services

In addition to improving patient outcomes, the purpose of the New Model of family medicine is to better define the role of family physicians and to help family physicians redesign their practices to support this role. Recent evidence points to dissatisfaction among many family physicians about the state of medical care. Family physicians have become increasingly frustrated in their ability to provide integrated care that is responsive to patients' current needs, prospective in offering preventive care, and financially rewarding.

\section{INTRODUCTION}

As a result of FFM recommendations, a sixth task force was created to formulate and recommend a financial model that sustains and promotes a thriving New Model of family medicine practice by focusing on practice reimbursement and health care finances. Specific task force goals were (1) to develop a financial model that assesses the impact of the New Model on practice finances, and (2) to recommend health care financial policies that, if implemented, would be expected to promote the New Model and the primary medical care function in the United States for the next few decades.

Task Force 6 agreed on several principles and assumptions that guided its financial modeling and analyses, findings and conclusions, and eventual recommendations. These assumptions are as follows:

- The US health care system currently performs at a level considerably below its potential: despite spending more on health care than any other nation, the United States does not boast the best health care indices or the most effective health care system. Payers and patients alike are looking for better value in health care, desiring better quality of care for less cost. ${ }^{7}$

- A strong and high-performing primary medical care infrastructure is essential to improving the performance and value of US health care.

- The development of such an infrastructure will require a major investment but will ultimately lead to more cost-effective health care.

- Without changes in the broader health care system and in the specialty, the viability of family medicine in the United States could become untenable during the next few decades, an outcome that would be detrimental to the health of the American public. ${ }^{1}$

- It is unlikely that the US health care system will increase overall health care expenditures for the purpose of enhancing the incomes of primary care physicians relative to those of other physician specialties; however, the current disparity in relative income levels needs to be addressed to assure an adequate primary care physician workforce for the future.

- Primary care physicians can increase their incomes by enhancing the value of their care to patients, payers, and purchasers of health care. Value is defined as the ratio of quality to cost. Value increases if quality increases and/or cost decreases.

- To increase the value of their care, family physicians must develop high-performance practices that are congruent with the 6 aims and 10 new rules outlined by the Institute of Medicine Crossing the Quality Chasm Report. ${ }^{8}$ The New Model proposed by the FFM should deliver the desired high level of practice performance and enable practices to meet the 6 aims and 10 rules.

- Implementation of the New Model should help family physicians "get off the hamster treadmill" and increase their practice satisfaction and incomes.

- Family physicians can also add value to the larger economic system by finding ways to keep workers healthy and on the job, thereby helping to reduce the costs of health-related work absenteeism.

- Family physicians may be able to increase their incomes through revenue sources not traditionally reimbursed by health insurance.

- Payment systems should be responsive to the needs of patients, including the need for a medical home and a personal physician. The reimbursement system should avoid placing the primary care physician in the role of dual agent, which can create a conflict of interest when the physician has incentives to limit care while trying to function as the patient's advocate.

- The care of patients with chronic diseases will be better when integrated and managed by a primary care physician in a high-performing New Model practice, obviating the need for chronic disease management carve-outs.

\section{METHODS}

To facilitate the work of Task Force 6, the Greenfield Consulting Group was asked to query focus groups in the same markets in which the original FFM research study was conducted for the purpose of vetting the New Model of family medicine with patients. A total of 6 focus groups were conducted in June of 2004 (2 groups of rural patients who had a family physician, 2 groups of inner-city patients who had a family physician, and 2 groups of suburban patients who did not have a family physician). A full description of the methods is available as supplemental data on the FFM Web site, which can be found at: www.futurefamilymed.org/taskforcesix.

It was determined that an outside consultant with expertise in health economics, health care finance, health policy, and practice management would be 
needed to assist Task Force 6 with developing the microeconomic (practice level) and macroeconomic (societal level) financial models necessary to achieve its goals. After a competitive bid process, the Lewin Group was selected to serve as consultants to the task force. The goal of the Task Force 6 research was to investigate and model selected aspects of the New Model to determine their impact (both expenses and revenue) on a family medicine practice. A full description of the methods is available as supplemental data on the FFM Web site at: www.futurefamilymed.org/ taskforcesix.

The consultants worked closely with Task Force 6 in the development of the financial models, and the task force incorporated model findings in this report. Two types of analyses were conducted by the consultant. First, the impact of the New Model on a family medicine practice was simulated within the current fee-for-service reimbursement environment. This exercise illustrated the micro perspective, because it related to individual physician practices. Second, alternative reimbursement mechanisms for the New Model were analyzed and presented. This broader perspective captures the macro implications of the New Model. The macro set of analyses built on microlevel analysis to estimate the impact of different reimbursement systems on family physicians. To assist in developing assumptions, the consultants reviewed existing literature on medical practices and conducted a series of interviews with industry experts. A total of 8 telephone interviews were completed with physicians and others involved in implementing aspects of the New Model. Many of the participants were using or assisted in implementing more than one of the features of the New Model, although none was experienced with all features.

The initial draft report of Task Force 6 findings and recommendations was shared with a reactor panel representing a broad spectrum of constituencies. Feedback from these individuals was reviewed and incorporated, as appropriate, into the final report of the task force.

\section{RESULTS}

\section{New Model Focus Group Results}

In June of 2004, focus group interviews were held with participants from Los Angeles, Boston, and rural Minnesota to evaluate the characteristics of the New Model.

Respondents were asked to allocate these characteristics into 3 categories based on their perceived importance when choosing a new primary care physician:

1. Most important and essential: personal medical home, commitment to provide family medicine's defined basket of services, advanced information sys- tems, patient-centered care, and elimination of barriers to access were considered most important and essential, in decreasing order of selection frequency.

2. Nice to have but not as essential/important as those allocated to the above group: team approach to care, whole-person orientation, and focus on quality and safety were ranked as nice to have, in decreasing order.

3. Not that important or essential: enhanced practice finance, redesigned offices, and care provided in a community context were ranked as just not that important or essential.

A more complete report on these findings can be found on the FFM Web site at: http://www.futurefamily med.org. ${ }^{9}$

\section{Financial Modeling Results}

The Lewin Group was engaged by Task Force 6 to assist in the development of a financial and reimbursement model for the New Model. This analysis was conducted using data specific for family physicians. It is likely that many of the elements of the New Model, as well as their projected impact on practice finances, will have relevance for other primary care practices, although considerable differences will arise based on the age, gender, morbidity, and payer mix of practices.

\section{Microlevel Analysis: Impact of New Model on Physician Practices}

A New Model of family medicine will have cost and income implications at the practice level. The New Model may require additional clinical staff to support the multidisciplinary team approach, new or revised information systems, and redesigned offices. On the other hand, some of the features, such as EHR systems, may reduce costs by reducing the need for administrative staff and increasing the amount of time physicians can spend in patient care. If a model is to be widely accepted and implemented, it must be feasible from a business perspective. In effect, physician practices must be able to implement and manage the New Model in a way that will yield adequate income to cover practice expenses as well as provide adequate net income to encourage a sufficient supply of family physicians in the future.

Modeling results are always sensitive to the underlying assumptions of the model. This is particularly true for this study of the New Model, which relies on assumptions involving implementation costs and physician and staff time and productivity.

Features of the New Model of Family Medicine Ten features of the New Model were identified that have a direct effect on practices and that are most amenable to modeling. These features encompass the full range of 
Table 1A. Magnitude of Assumed Impacts of New Model of Family Medicine

\begin{tabular}{|c|c|c|c|c|}
\hline \multirow[b]{2}{*}{$\begin{array}{l}\text { New Model } \\
\text { Feature }\end{array}$} & \multicolumn{4}{|c|}{ Practice Outcome } \\
\hline & $\begin{array}{l}\text { Up-Front } \\
\text { Training Costs }\end{array}$ & $\begin{array}{l}\text { Number } \\
\text { of Services }\end{array}$ & $\begin{array}{l}\text { RVUs per } \\
\text { Service }\end{array}$ & $\begin{array}{l}\text { Physician Time } \\
\text { per Service }\end{array}$ \\
\hline Open-access scheduling & None & $-6.5 \%$ & $10 \%$ & None \\
\hline Online appointment & $1 \mathrm{~d} \times 2$ administrative staff & None & None & None \\
\hline Electronic health records & $3 \mathrm{~d} \times$ number of users & None & $1 \%$ & $-5 \%$ \\
\hline Group visit & $\begin{array}{l}2 \mathrm{~d} \text { for } 1 \mathrm{MD} / \mathrm{DO}+2 \mathrm{~d} \text { per clinical } \\
\text { staff person }\end{array}$ & None & None & $-50 \%$ \\
\hline E-visits & None & None* & None & Half of CPT 99212 \\
\hline Chronic disease management & None & None & None & None \\
\hline Web-based information & Part of office expenses & None & None & None \\
\hline Team approach (leveraging staff) & $\begin{array}{l}\$ 2,000+5 \mathrm{~d} \text { for } 1 \mathrm{MD} / \mathrm{DO} \\
\quad+5 \mathrm{~d} \text { per clinical staff person }\end{array}$ & None & None & $-5 \%$ \\
\hline Clinical practice guideline software & $\begin{array}{l}\$ 2,000+3 \mathrm{~d} \text { for } 1 \mathrm{MD} / \mathrm{DO} \\
\quad+3 \mathrm{~d} \text { per clinical staff person }\end{array}$ & None & None & $-3 \%$ \\
\hline Outcomes analysis & $\begin{array}{l}5 \mathrm{~d} \text { for } 1 \mathrm{MD} / \mathrm{DO} \text { and clinical } \\
\text { staff person }\end{array}$ & None & None & $5 \mathrm{~d} / \mathrm{y}$ \\
\hline
\end{tabular}

Table 1B. Magnitude of Assumed Impacts of New Model of Family Medicine

\begin{tabular}{|c|c|c|c|c|}
\hline \multirow[b]{2}{*}{$\begin{array}{l}\text { New Model } \\
\text { Feature }\end{array}$} & \multicolumn{4}{|c|}{ Practice Outcome } \\
\hline & $\begin{array}{c}\text { Clinical Staff Time } \\
\text { per Service }\end{array}$ & $\begin{array}{l}\text { Office } \\
\text { Expense }\end{array}$ & $\begin{array}{l}\text { Administrative } \\
\text { Staff }\end{array}$ & $\begin{array}{l}\text { Malpractice } \\
\text { Premium }\end{array}$ \\
\hline Open-access scheduling & None & None & None & None \\
\hline Online appointment & None & $\$ 1,920 / y$ & $\begin{array}{c}-10 \% \text { in reception } \\
\text { time and cost }\end{array}$ & None \\
\hline Electronic health records & $-5 \%$ & $\begin{array}{r}\$ 35,000 \text { per MD/DO, } \\
\text { amortized over } 5 \text { y }\end{array}$ & $-10 \%$ & $-5 \%$ \\
\hline Group visit & $-50 \%$ & $\$ 250$ per group visit & None & None \\
\hline E-visits & Half of CPT 99212 & $\$ 3,000$ & None & None \\
\hline Chronic disease management & 1 RN per 200 patients & None & None & None \\
\hline Web-based information & None & $\$ 10,000 / y$ & Part of office expenses & None \\
\hline Team approach (leveraging staff) & $+5 \%$ & None & None & None \\
\hline Clinical practice guideline software & $+3 \%$ & None & None & None \\
\hline Outcomes analysis & $5 \mathrm{~d} / \mathrm{y}$ & None & None & None \\
\hline
\end{tabular}

changes entailed in the New Model. These components include:

1. Open-access scheduling

2. Online appointments

3. EHRs

4. Group visits

5. E-visits

6. Chronic disease management

7. Web-based information

8. Team approach, where clinical staff are more involved in providing care

9. Use of clinical practice guideline software

10. Outcomes analyses

A number of family physicians have already incorpo- rated some of the features of the New Model into their practices. ${ }^{10-12}$ Task Force 6 was not aware of any practices that had adopted all the features of the New Model.

\section{Assumptions: Relationship Between the New Model and Practice Outcomes}

One of the greatest challenges in modeling the New Model is that each of these elements affects practice costs and revenues in different ways. To assist in developing the assumptions, existing literature on medical practices was reviewed and interviews with industry experts were conducted.

Table 1 displays a summary of the expected impacts the New Model will have on aspects of practice out- 
comes. The impact of each feature of the New Model was considered for the following:

1. Up-front training requirements

2. Number of services performed

3. Service intensity (ie, revenue or relative value units [RVUs] per procedure)

4. Physician time per service

5. Clinical staff time per service

6. Office expenses (eg, information technology, building and occupancy costs, office furniture and equipment)

7. Administrative staff costs

8. Malpractice premiums

The assumed magnitude of the relationships among the different features of the New Model and the practice outcomes of interest used in the model were based on the literature reviewed ${ }^{13}$ and interviews with practices that have implemented different features of the New Model.

\section{Open-Access Scheduling}

Under the open-access scheduling model, the practice typically leaves $50 \%$ to $65 \%$ of office visit slots free. These slots are then filled each day based upon requests received since the end of the previous work day. This enables patients to be seen by the physician or physician extenders on the same day.

The available research indicates that open-access scheduling results in an overall reduction in the number of visits per patient and an offsetting increase in the intensity of services provided, as measured by RVUs. Much of the increase in RVUs per visit appears to be an increase in the proportion of patients seeing their own primary care physician. The data indicate that the number of visits per patient declines by about $6.5 \%$ while the amount paid increases by about $\$ 4.46$ per visit (approximately 10\%). ${ }^{10}$ These data indicate that open-access scheduling increases physician income while it reduces physician hours.

\section{Online Scheduling}

Web-based scheduling permits patients to make an appointment without talking to the medical receptionist. This service is integrated with the office-based system so that the receptionist can continue to make appointments. Although this service requires an up-front expenditure for software or a monthly subscription fee for a Web-based service, online scheduling potentially reduces the amount of time required for medical receptionists. There is little information on the cost to a practice generated by an online scheduling capability.

The effect of a Web-based scheduling approach was simulated by assuming that an online scheduling service is used for an annual cost of $\$ 1,920 .{ }^{14}$ In addition, the system was assumed to require 1 day of training for no more than 2 administrative staff.

\section{Electronic Health Records}

An EHR system records the results of every physician visit, including medical complaints and diagnoses, test results, patient histories, and treatments used, while supporting electronic prescribing and ordering, as well as electronic diagnostic test results. It is assumed that an EHR improves physician and clinical productivity by reducing the time and effort required to pull medical charts. ${ }^{15}$ In addition, an EHR that is integrated with a practice management system simplifies the billing process. An EHR system can also be used to conduct outcomes analyses. It can include imbedded clinical decision support tools to be used in various visits. Because an EHR allows physicians to better document the services they provide, it is expected that it will help physicians bill more accurately and reduce the tendency for cautious billing. ${ }^{16}$ Finally, it is assumed that an EHR may help reduce medical liability premiums by providing more readily available patient histories, drug interaction warnings, and better documentation of past treatments, diagnoses, and symptoms.

\section{Group Visits}

Under the group visits model, the physician practice arranges for a meeting of patients with similar needs that is conducted by the physician and a clinical professional, such as a nutritionist or family therapist. Sessions typically involve patient education concerning areas of common concern to the group, as well as the management of individual health problems of group members. For example, a group visit on nutrition and other relevant factors could be conducted with 10 to 20 diabetic patients; at the same time, each participant's diabetes screening laboratory studies could be updated. Sessions typically last for 1 to 2 hours. The practice bills insurers for the cost of a visit for each of the patients.

It is assumed that each group visit is led by 1 nurse and 1 physician for 15 patients. ${ }^{17}$ Up-front training requires 2 days for the leading physician and nurse. It is also assumed that the practice will pay an additional $\$ 250$ per session for space for the group visit, and that group visits occur 48 weeks out of the year. Group visits replace individual visits for the Current Procedural Terminology (CPT) code 99212, 99213, or 99214 (evaluation and management for established patients). It is assumed that the physician and clinical staff time required to perform 1 evaluation and management service for each patient is reduced by one half, and there will be 1 group visit per week per physician. 
Online E-Visits

An important part of the New Model is the use of e-mail to communicate with patients. E-mail can be used to answer questions, request refill prescriptions, and deal with other issues that do not require an office visit. Most insurers do not cover e-mail communications with patients even though such communications can be especially useful in day-to-day management of chronic conditions.

Despite the lack of reimbursement, many physicians use e-mail in the same manner that physicians often communicate with patients by telephone without reimbursement. One of the benefits of e-mail is that it enables physicians to avert unneeded office visits, which can be especially useful in an environment where the demand for physician services exceeds the supply of available physician time.

Evidence on the cost and revenue effects of e-visits is limited. There is one pilot study showing that reimbursing physicians for e-visits (ie, $\$ 25$ per e-visit up to 25 e-visits per year) results in an overall reduction in spending for physician care of about $\$ 1.92$ per person per month, and a reduction in other health care costs of $\$ 1.77$ per person per month. ${ }^{18}$ Thus, even if physicians are paid for these visits, their revenues decline. The savings in time, however, makes it possible for the physician to increase the number of office visits provided, resulting in a net increase in income.

Unfortunately, there is no evidence of the impact of e-visits in a fee-for-service system in which these consultations are not covered. Presumably, in this situation, the physician would restrict use of e-visits to limit the loss of revenue. For illustrative purposes, it is assumed that the physician conducts e-visits for $25 \%$ of his or her low-level evaluation and management visits for established patients (CPT 99212).

\section{Chronic Disease Management}

Chronic disease management is a primary care tool designed to help patients with chronic conditions reduce the incidence and intensity of the effects of these conditions. Examples include consultations concerning diet, maintenance of medications, and coordination of care and disease management. Although these services are sometimes provided by the physician, they are more often provided by nurses, dietitians, and other clinical staff. Chronic disease management typically is not separately reimbursed by insurers.

In this analysis, it is assumed that chronic disease management affects costs for the clinical staff. It is assumed that a licensed nurse is assigned to manage a case load of 200 patients, and that each practice provides intensive chronic disease management for $2 \%$ of its patients. Although probably considerably less than the percentage of a physician's panel with a chronic condition, this $2 \%$ represents patients that would benefit most from an intensive chronic disease management program.

The increased use of chronic disease management is expected to result in fewer emergency department visits and fewer visits with other physician specialists. These offsets are included in the analysis of macro effects and changes in reimbursement systems in another part of the project. In addition, chronic disease management is likely to increase patient contacts with physicians, although additional contacts would require additional physician time. Because the analysis primarily focuses on the impact of the New Model on physician income under current work hours, it is assumed that any increase in services associated with chronic care patients is offset by a reduction in the physician's panel size, so that the number of hours worked by a physician remains unchanged.

\section{Web-Based Information System}

A primary feature of the New Model is the use of the Web to distribute information to patients on their health conditions and the latest developments in treatments. Some hospitals and large practices have developed extensive Web sites that provide this information and update materials as new information becomes available. Whereas developing such sites may be an expensive proposition for an individual physician practice, small Web sites could be developed to provide the information most relevant to their patients. Such Web sites could also include links to other systems that provide additional information in much greater detail.

Although these Web sites are expected to have minimal impact on the frequency and intensity of patient visits, they would increase nonclerical personnel costs associated with maintaining the Web site. These costs may be offset by reducing the amount of paper information the practice must provide to patients. Also, the Web sites could attract patients to practices seeking to increase patient volume.

For illustrative purposes, it is assumed that a practice establishes a Web site using an outside contractor. The assumed cost of development and maintenance of the Web site is $\$ 10,000$ per year. It is worth noting that the American Academy of Family Physicians (AAFP) has a service whereby members can set up a Web site free of charge. As a result, $\$ 10,000$ per year may be an overestimate for some family physicians.

\section{Team Approach (Leveraging Clinical Staff)}

One key element of the New Model is a team-based approach to providing care. This approach can improve the productivity of a practice by leveraging clinical staff while making full use of their training. ${ }^{8,19}$ Such a 
model has the potential to enable physicians to serve a far larger panel of patients by using clinical staff to perform routine tasks that do not require the expertise of a physician. There are many examples of this model:

- Clinical staff can be used to gather certain aspects of the patient history and enter it into the EHR, where it is available for review by the physician.

- Clinical staff can be used to counsel patients on physician-prescribed drug therapy, including a description of the drug and its potential side-effects, do's and don'ts (eg, mixing with alcohol), and monitor the patient's progress.

The physician is recognized by patients as the leader of the team, and the centrality of the physician-patient relationship is maintained. At the same time, the importance of the relationship between team and patient is broadened. This approach reduces the amount of time spent by the physician per patient, which frees the physician to perform additional services and focus on less routine care. Leveraging permits physicians to increase their income by increasing the volume of services provided.

\section{Clinical Practice Guidelines Software}

Newly available software systems provide clinical practice guidelines tailored to suit individual patient conditions. The software takes the form of a clinical decision-support system that helps guide clinical staff and the physician through a diagnosis and treatment algorithm based on evidence-based research on best practices. Use of such systems is believed to improve the physician's ability to diagnose patient health conditions correctly and treat them appropriately. ${ }^{20}$ Moreover, clinical decision support systems are useful for standardizing care by all physicians within a practice. Ideally, these systems would be embedded into the EHR.

The impact of adopting this type of practice guideline on the net revenues of family practice is unclear. First, the system could enable mid-level clinicians to offer routine care to established patients. Thus, the software system would be used to help physicians better leverage clinical staff. Such systems could also lead to increased use of recommended tests and treatments, while reducing emergency department visits and other costs associated with untreated conditions. Use of such systems can increase costs for primary care, however, and there is no evidence of the impact of medical practice guidelines on primary care physician utilization and revenues. It is assumed that the use of clinical practice guidelines allows physicians to rely more effectively on a team approach to medicine and leverage their time. The assumptions are therefore similar to those described above for team approach.

\section{Outcomes Analysis}

Physician practices can develop outcomes indicators for use in evaluating their own performance and providing patients with information on the quality of the care they provide. Potential examples include the achievement of certain parameter targets in patients with chronic diseases (eg, blood pressure, glycosylated hemoglobin levels), hospitalization rates, patient satisfaction with care, and so on. This analysis assumes that the practice has adopted an EHR which provides the data needed to develop the various outcomes measures. It assumes that the outcomes measurement process has no direct effect on visits, procedures, and costs for delivering medical care. It assumes that there is an annual cost to developing and assessing the outcomes data.

\section{Approach for Simulating the Impact of the New Model}

To estimate the impact of the New Model, a financial model for an average practice was developed. The financial outcomes for this practice serve as a benchmark for the analysis. The impact of different features of the New Model on physician income and hours worked was then simulated. These effects were measured as incremental changes to the benchmark values. The financial model depends on practice size, practice expenses, service mix, payer mix, physician work hours, and physician productivity (ie, RVUs per physician or unit of time).

\section{Development of a Base Case: An Average Practice} To develop values for the average practice, medical revenues and costs were modeled using Healthcare Common Procedure Coding System (HCPCS)-level information and an expected distribution of services for a typical family physician's practice. The task force recognized that every practice is unique; there is no average practice. Nonetheless, the development of a model to estimate financial impact required the use of a base case, or average practice. Survey data from the AAFP indicate that the most common practice setting for a family physician is a single-specialty group with 5 family physicians.

The distribution of services and supplies for approximately 3,071 family physicians was obtained from Physcape, a subsidiary of the Medical Group Management Association, for the 24-month period from January 1, 2001, to December 31, 2002. Using this distribution of services and supplies, the revenues and costs of providing these services were estimated using data from the Centers for Medicare and Medicaid Services, and Relative Value Studies, Inc. Table 2 highlights the key components of the model and data sources used. 


\begin{tabular}{|c|c|c|}
\hline $\begin{array}{l}\text { Financial Model } \\
\text { Component }\end{array}$ & Inputs to Model & Data Sources \\
\hline Revenue & $\begin{array}{l}\text { Reimbursement levels (ie, price) } \\
\text { Quantity (ie, mix and number } \\
\text { of services) }\end{array}$ & $\begin{array}{l}\text { Physcape (service mix) } \\
\text { Medicare RBRVS (RVUs) } \\
\text { AMA Physician Socioeconomic Statistics } \\
\text { (payer mix) }\end{array}$ \\
\hline Expenses & $\begin{array}{l}\text { Medical supply expenses } \\
\text { Medical equip expenses } \\
\text { Clinical staff expenses } \\
\text { Medical liability } \\
\text { Office expenses } \\
\text { Administrative staff expenses } \\
\text { and other indirect expenses }\end{array}$ & $\begin{array}{l}\text { AMA/MGMA data (overall direct and } \\
\text { indirect practice expenses, physician } \\
\text { salary, medical liability) } \\
\text { CMS Clinical Practice Expense Panels } \\
\text { data } \\
\text { CMS physician time data } \\
\text { Bureau of Labor Statistics (salaries) }\end{array}$ \\
\hline $\begin{array}{l}\text { Physician hours } \\
\text { worked }\end{array}$ & $\begin{array}{l}\text { Patient care hours } \\
\text { Total hours }\end{array}$ & $\begin{array}{l}\text { AAFP Practice Profile Survey } \\
\text { AMA physician socioeconomic statistics }\end{array}$ \\
\hline
\end{tabular}

\section{Key Drivers of Financial Model}

\section{for an Average Practice}

One key driver of the financial model is the number of physician patient care hours. This number determines the volume of services for the practice and, therefore, the level of revenues and costs. Although simplified, the estimates for the base case are derived using the following formulas:

$$
\begin{gathered}
\text { Service volume }=\begin{array}{c}
\text { Number of services } \\
\text { per hour }
\end{array} \times \begin{array}{c}
\text { Physician patient care hours } \\
\text { (hours in direct patient care) }
\end{array} \\
\begin{array}{c}
\text { Average payment } \\
\text { per service }
\end{array}=\begin{array}{c}
\text { Medicare } \\
\text { conversion } \\
\text { factor }
\end{array} \times \begin{array}{c}
\text { Average RVUs } \\
\text { per service }
\end{array} \times \begin{array}{c}
\text { Payer mix } \\
\text { adjustment }
\end{array} \\
\text { Revenues }=\left(\begin{array}{c}
\text { Service } \\
\text { volume }
\end{array} \times \begin{array}{c}
\text { Average payment } \\
\text { per service }
\end{array}\right)-\begin{array}{c}
\text { Unpaid services } \\
\text { (ie, bad debt) }
\end{array} \\
\text { Costs }=\left(\begin{array}{c}
\text { Service } \\
\text { volume }
\end{array} \times \text { Direct costs per service }\right)+\begin{array}{c}
\text { Indirect costs } \\
\text { for the practice }
\end{array}
\end{gathered}
$$

In addition to patient care hours, other important inputs into the model are service mix (which determines number of services per hour and direct costs per service), payer mix, and relative reimbursement levels among payers.

\section{Findings for an Average Practice}

\section{Assumptions}

Table 3 shows the assumptions regarding average hours worked by physicians. This information was obtained from the 2003 AAFP Practice Profile Survey. In the model, physicians are assumed to work full time, which is defined as 2,397 $\mathrm{h} / \mathrm{y}$. An important component of the model is the number of clinical staff, which was estimated based on the volume of services provided. Table 4 shows the assumptions relating to payment levels and payer mix In addition to these assumptions, $10 \%$ of physician services were assumed to be uncompensated care, including charity care $(8 \%)$ and bad debt (2\%).

\section{Physician Output and Income for the Base Case}

The distribution of services from the Physcape data, the number of hours worked, and Centers for Medicare and Medicaid Services data on physician time by service were used to approximate the volume of visits and procedures for a physician by service category. These figures are shown in Table 5, along with their associated total RVUs. Based on these output measures, the revenues, costs, total compensation, and income for a practice with 5 physicians were estimated. The results are shown in Table 6 . Based on these assumptions, an average total physician compensation of $\$ 167,457$ is estimated. Assuming that income accounts for $85 \%$ of physician compensation and that benefits account for $15 \%$ of compensation, the model estimates an average physician pretax income of $\$ 142,338{ }^{25}$ This figure, which approximates the average annual income of $\$ 140,500$ reported by family physicians responding to the 2004 AAFP Practice Profile Survey, reflects the

\begin{tabular}{lc|}
\hline Table 3. Physician Activity Assumptions \\
\hline Weeks worked per year & 47 \\
Total hours worked per week & 51 \\
Patient care hours per week & 40 \\
Other professional activities per week & 11 \\
Total patient care hours per physician per year & 1,880 \\
Total hours per physician per year & 2,397 \\
\hline Source: 2003 AAFP Member Profile Survey. Physician Socioeconomic Status: 2000- \\
2002 Edition. American Medical Association, Center for Health Policy Research, \\
2001 also reports 50.6 h/wk (patient care), 4.4 h/wk (other) ${ }^{21,22}$ \\
\hline
\end{tabular}

Table 4. Payer Mix and Payment Level Assumptions

\begin{tabular}{lcc}
\hline Payer & $\begin{array}{c}\text { Payment Levels Relative } \\
\text { to Commercial Payers }\end{array}$ & $\begin{array}{c}\text { Percent of } \\
\text { Revenues }\end{array}$ \\
\hline Commercial & 1.00 & 45 \\
Medicare & 0.83 & 27 \\
Medicaid & 0.53 & 13 \\
Self-pay & 1.20 & 16 \\
\hline Source: Lewin Group, ${ }^{13}$ Wassenaar \& Thran, ${ }^{22}$ Direct Research ${ }^{23}$ and Norton. ${ }^{24}$ \\
\hline
\end{tabular}




\begin{tabular}{|lcr|}
\hline \multicolumn{3}{l}{ Table 5. Physician Output and Productivity } \\
\hline Services & $\begin{array}{c}\text { Number } \\
\text { of Services }\end{array}$ & $\begin{array}{c}\text { Total } \\
\text { RVUs }\end{array}$ \\
\hline Services & & \\
Evaluation and management & 5,281 & 8,305 \\
Medicine & 729 & 389 \\
Radiology & 263 & 315 \\
Surgery & 1,026 & 808 \\
Other & 73 & 54 \\
Total services per physician & 7,371 & 9,872 \\
Other services & & \\
Drugs & 263 & - \\
Medicine (non RVu) & 383 & - \\
Pathology/laboratory testing & 2,577 & - \\
Other & 203 & - \\
Total other services per physician & 3,426 & - \\
All services per physician & 10,797 & 9,872 \\
\hline Source: Lewin Group estimates. ${ }^{13}$ & & \\
RVu = relative value unit. & & \\
\hline
\end{tabular}

income for a full-time physician who shares equally in the income of the practice. Because of the ability to share fixed costs, the model estimates slightly higher average income for physicians in larger practices. For example, for 3-and 7-physician practices, the model estimates average physician income of $\$ 138,199$ and $\$ 144,112$, respectively. The income presented in Table 6 serves as a benchmark value when considering the impact of the New Model.

The 5,281 evaluation and management services per year translate into approximately 112 evaluation and management visits per week per physician (assuming a physician works 47 weeks per year). This average is roughly $8 \%$ higher than the average number of visits reported in the AAFP 2003 Practice Profile Survey and roughly $11 \%$ lower than the average number of visits reported by family physicians in the AMA Pbysician Socioeconomic Statistics: 2000-2002 Edition.

\section{Impact of the New Model on Physicians: Transition Costs and Income}

Physician Income and the New Model

of Family Medicine

Table 7 reports the results of the simulation of the impact of the New Model for a practice with 5 physicians. Using the assumptions presented in the sections above, there are important potential increases in income as a result of implementing designated features of the New Model. Overall, it is estimated that a fulltime physician could increase total income (assuming the same ratio of income to total compensation) by $26 \%$ if all features of the model were implemented and the physician continued to work the same number
Table 6. Benchmarking Values for Physician Income (in 2004 Dollars)

\begin{tabular}{|c|c|c|c|}
\hline Source & $\begin{array}{l}\text { Revenue } \\
\text { (\$) }\end{array}$ & $\begin{array}{l}\text { Costs } \\
(\$)\end{array}$ & $\begin{array}{c}\text { Compensation } \\
\text { (\$) }\end{array}$ \\
\hline \multicolumn{4}{|l|}{ Payer } \\
\hline Commercial & $1,003,213$ & 529,965 & 473,248 \\
\hline Medicare & 609,576 & 322,019 & 287,557 \\
\hline Medicaid & 287,918 & 152,098 & 135,820 \\
\hline Self-pay & 348,650 & 184,181 & 164,470 \\
\hline Total for practice & $2,249,357$ & $1,188,262$ & $1,061,095$ \\
\hline Bad debt & 43,862 & - & - \\
\hline Charity care & 179,949 & - & - \\
\hline Net for practice & $2,025,546$ & $1,188,262$ & 837,284 \\
\hline $\begin{array}{l}\text { Total compensation } \\
\text { per physician }\end{array}$ & 405,109 & 237,652 & 167,457 \\
\hline $\begin{array}{l}\text { Income per } \\
\text { physician }\end{array}$ & - & - & 142,338 \\
\hline $\begin{array}{c}\text { Benefits per } \\
\text { physician }\end{array}$ & - & - & 25,119 \\
\hline
\end{tabular}

of hours. If a physician used increases in productivity created by implementing the New Model to reduce hours worked, income is estimated to fall by $12 \%$. This reduction in income is less than the reduction of hours worked, which is estimated to be approximately $18 \%$ of total physician work hours.

Table 8 shows the trade-off between income and total hours worked under the New Model. At the current level of hours worked by family physicians (51), total compensation and income for a physician are $\$ 167,457$ and $\$ 142,338$, respectively (see Table $6)$. According to the model, a family physician could achieve the current level of compensation and income under the New Model by working approximately 45 hours or approximately $12 \%$ fewer hours. If a physician continues to work 51 hours per week, compensation and income increase to $\$ 210,288$ and $\$ 178,745$, respectively, under the New Model. Alternatively, a physician could choose to take all increases in productivity as reduced work hours. As shown in Table 7, this would result in a reduction of compensation by $12 \%$ to $\$ 146,553$. In this instance, the physician would work 42 hours per week or almost $18 \%$ less than current levels.

Impact of the New Model by Practice Size This section shows the impact of the New Model for practices of different sizes. These results are reported in Table 9 for practices of 1, 3, 5, 7, and 9 physicians. The baseline income values are different, because of the assumptions regarding indirect costs. It is generally assumed that $65 \%$ of these costs will vary with the number of physicians in a practice. 


\begin{tabular}{|c|c|c|}
\hline \multirow[b]{2}{*}{ Feature of New Model } & \multicolumn{2}{|c|}{$\begin{array}{c}\text { Change in Compensation } \\
\text { Per Physician }\end{array}$} \\
\hline & $\begin{array}{l}\text { With Reduction } \\
\text { in Hours } \\
\text { Worked (\$) }\end{array}$ & $\begin{array}{l}\text { With Current } \\
\text { Work Hours } \\
\text { (\$) }\end{array}$ \\
\hline Open access scheduling & 9,133 & 9,133 \\
\hline Online appointment & 5,752 & 5,752 \\
\hline Electronic health records & 3,398 & 15,573 \\
\hline Group visits & $(8,769)$ & 15,411 \\
\hline E-visits & $(7,649)$ & $(3,786)$ \\
\hline Chronic disease management & $(8,591)$ & \\
\hline Web-based information & $(2,000)$ & $(2,000)$ \\
\hline Leverage clinical staff & $(6,121)$ & 9,699 \\
\hline $\begin{array}{l}\text { Clinical practice guideline } \\
\text { software }\end{array}$ & $(3,877)$ & 5,664 \\
\hline Outcomes analysis & $(2,180)$ & $(2,180)$ \\
\hline $\begin{array}{l}\text { Change in compensation } \\
\text { with new model }\end{array}$ & $(20,904)$ & 42,831 \\
\hline $\begin{array}{l}\text { Average compensation } \\
\text { per physician }\end{array}$ & 167,457 & \\
\hline Total compensation per physician & 146,553 & \\
\hline Change, \% & -12 & 26 \\
\hline \multicolumn{3}{|l|}{ Source: Lewin Group estimates. ${ }^{13}$} \\
\hline \multicolumn{3}{|c|}{ Note: numbers in parentheses indicate loss. } \\
\hline
\end{tabular}

Transition Costs and the New Model of Family Medicine

The cost of the transition from the existing model of care to the New Model will vary by practice, depending on the extent to which the practice has already incorporated features of the New Model as well as other factors (eg, physical plant of the practice, existing staff, etc). That said, estimates of the transition costs for many of the features can be made based on experience with implementing those features in isolation (rather than as part of a wholesale transition).

Transition costs include the following:

1. Initial purchase price of necessary equipment and supplies (ie, capital costs)

2. Recruiting new personnel, as needed

3. Training existing personnel

4. Lost productivity

These are up-front, one-time costs (both direct and indirect) required to move from the current practice state to the New Model. They do not include other costs associated with the New Model (eg, maintenance of the EHR, performance of outcomes analysis, etc), which are described and accounted for elsewhere in this report.
Table 8. Trade-off Between Hours Worked and Income

\begin{tabular}{ccc}
\hline $\begin{array}{c}\text { Hours Worked } \\
\text { Weekly }\end{array}$ & $\begin{array}{c}\text { Total } \\
\text { Compensation (\$) }\end{array}$ & $\begin{array}{c}\text { Income } \\
\mathbf{( \$ )}\end{array}$ \\
\hline 40 & 132,104 & 112,288 \\
41 & 139,184 & 118,306 \\
42 & 146,272 & 124,331 \\
43 & 153,366 & 130,361 \\
44 & 160,465 & 136,395 \\
45 & 167,570 & 142,435 \\
46 & 174,679 & 148,477 \\
47 & 181,793 & 154,524 \\
48 & 188,911 & 160,574 \\
49 & 196,033 & 166,628 \\
50 & 203,159 & 172,685 \\
51 & 210,288 & 178,745 \\
52 & 217,420 & 184,807 \\
53 & 224,555 & 190,872 \\
54 & 231,694 & 196,940 \\
55 & 238,835 & 203,010 \\
\hline
\end{tabular}

Source: Lewin Group estimates. ${ }^{13}$

Note: Income was derived from total compensation by assuming that income is $85 \%$ of total physician compensation. The result likely understates income at more than 51 work hours and overstates income at less than 51 hours, because income will rise as a percentage of total compensation as compensation increases.

Table 10 attempts to specify what is known about transition costs based on experience reported in the literature. The following assumptions are used in making these estimates:

- A 5-physician practice (the benchmark case as in Table 6)

- One nonphysician clinician (eg, nurse-practitioner or a physician's assistant) (based on a full-time-equivalent ratio from the Medical Group Management Association Cost Survey, 2003 Report Based on 2002 Data)

- Physician productivity = net practice revenue per physician $(\$ 405,109)$ (Table 6)

- Nonphysician clinician productivity $=53 \%$ of physician productivity $(\$ 214,708)$ (based on compari-
Table 9. Impact of the New Model on Income by Practice Size (No Change in Hours Worked)

\begin{tabular}{lccccc}
\hline & \multicolumn{5}{c}{ Physicians in the Practice } \\
\cline { 2 - 6 } Practice Characteristic & $\mathbf{1 *}$ & $\mathbf{3}$ & $\mathbf{5}$ & $\mathbf{7}$ & $\mathbf{9}$ \\
\hline $\begin{array}{l}\text { Income per physician } \\
\quad \text { (current baseline) }(\$)\end{array}$ & 131,949 & 138,199 & 142,338 & 144,112 & 145,097 \\
$\begin{array}{l}\text { Income per physician } \\
\quad \text { under New Model }(\$)\end{array}$ & 143,316 & 170,600 & 178,744 & 182,265 & 184,229 \\
Percent change & 9 & 23 & 26 & 26 & 27 \\
\hline
\end{tabular}

Source: Lewin Group estimates. ${ }^{13}$

*Solo practice that provides pathology and laboratory testing. Results are similar for a solo practice that does not provide pathology and laboratory testing in office. 
Model on physician costs and revenues. These are highly sensitive to the selected assumptions, which are documented below.

The estimated changes in net physician compensation presented in this section include both cash income and benefits. In general, little incremental change is expected to occur in benefits, and most of the incremental change will occur in cash income.

\section{Covering Elements of the New Model}

\section{Not Reimbursed Under Fee-for-Service}

As discussed above, average physician compensation can be increased by about $\$ 42,800$ per year under the New Model (assuming patient volume adjusts to capacity). This amount would raise per-physician compensation from about $\$ 167,500$ under current practices to about $\$ 210,300$, assuming physicians use the time saved under the New Model to increase the number of patients served or services provided, and assuming that there is a demand for an increased volume of services.

Some elements of the New Model, such as chronic disease management and e-visits, are not covered under existing fee-for-service reimbursement models. In this section, the impact of reimbursing physicians for e-visits and chronic disease manage-

ment is illustrated.

Reimbursement for E-visits. Physicians typically are not reimbursed for patient consultations provided through e-mail and the Web. It appears that adopting e-visits within the current feefor-service system would actually reduce physician revenues by reducing the number of reimbursable office visits. In fact, the available evidence indicates that even should e-visits become reimbursable, they would still result in a reduction in physician revenues because they are reimbursed at a rate lower than an office visit. One study showed that reimbursing for these services actually reduced health care spending by about $\$ 3.69$ per patient per month, of which about $\$ 1.92$ was a net reduction in payments to primary care physicians. ${ }^{18}$

Reimbursement for Chronic Disease Management. Another element of the New Model that is generally not reimbursed by health plans is chronic disease management. Some private insurers do reimburse for these services, but these programs typically limit the payment to care provided to patients who have in some way been registered as having some chronic illness. Although reimbursement methods differ, the insurer will often pay for an initial visit with the physician to initiate the process. The care manager or physician is then paid a monthly amount per patient to provide ongoing chronic disease management, typically provided by a nurse. Monthly payments can vary with the disease, but typically average and conservative estimates call for about $\$ 15$ per month per chronically ill patient.

The impact that reimbursement for chronic disease management will have on physicians is estimated assuming $10 \%$ of all of the patients served by each physician have one or more chronic illnesses that qualify for the benefits (assumes an average patient panel of 2,030 patients per full-time-equivalent physician) and that physicians are reimbursed $\$ 15$ per eligible patient per month. It is estimated that chronic disease management reimbursement under these assumptions will result in an increase in physician compensation of about $\$ 14,834$ per full-time-equivalent physician, with current hours worked (Table 11).

\section{Table 11. Change in Physician Compensation Under New Model, by Payment Category With Payments for E-visits and Chronic Disease} Management in 2004

\begin{tabular}{|c|c|c|}
\hline Payment Category & $\begin{array}{l}\text { With } 18 \% \text { Reduction } \\
\text { in Hours Worked, } \$\end{array}$ & $\begin{array}{l}\text { With Current } \\
\text { Work Hours,* \$ }\end{array}$ \\
\hline \multicolumn{3}{|l|}{ Current average compensation } \\
\hline Mean compensation per FTE physician ${ }^{\dagger}$ & 167,500 & 167,500 \\
\hline \multicolumn{3}{|l|}{ Changes in compensation per FTE physician } \\
\hline $\begin{array}{l}\text { New Model within current FFS model } \\
\text { (from microanalysis) }\end{array}$ & $(20,900)$ & 42,800 \\
\hline With e-visit reimbursement ${ }^{\ddagger}$ & 4,631 & 4,715 \\
\hline $\begin{array}{l}\text { Chronic disease management } \\
\text { reimbursement }{ }^{\S}\end{array}$ & 12,213 & 14,834 \\
\hline Total change in compensation & $(4,056)$ & 62,349 \\
\hline \multicolumn{3}{|l|}{ Total compensation under policy } \\
\hline Total physician compensation & 163,444 & 229,849 \\
\hline \multicolumn{3}{|c|}{ Source: Lewin Group estimates using illustrated assumptions. ${ }^{13}$} \\
\hline \multicolumn{3}{|l|}{ Note: numbers in parentheses indicate loss. } \\
\hline \multicolumn{3}{|l|}{ FTE = full-time-equivalent; FFS = fee-for-service. } \\
\hline \multicolumn{3}{|c|}{$\begin{array}{l}\text { * Assumes physicians use savings in time worked to increase patient volume to maintain total hours worked per week. } \\
\text { † Assumes all patients are enrolled in participating health plans. Assumes average panel of 2,030 patients per } \\
\text { FTE physician. }\end{array}$} \\
\hline \multicolumn{3}{|c|}{$\begin{array}{l}\text { ₹ Assumes that e-visits are reimbursed at } \$ 25 \text { per consultation up to a maximum of } 25 \text { consultations per patient } \\
\text { per year. }\end{array}$} \\
\hline \multicolumn{3}{|c|}{$\begin{array}{l}\S \text { Assumes chronic disease management is reimbursed at } \$ 15 \text { per month for people with chronic illnesses. As in } \\
\text { the micromodel section, the model assumes that a practice care manages only } 2 \% \text { of its patients. Because chronic } \\
\text { disease management is expensive, this assumption is maintained throughout where chronic disease management is } \\
\text { not directly reimbursed. If chronic disease management is directly reimbursed, it is assumed that } 10 \% \text { of patients } \\
\text { are care managed. In addition, } 2 \% \text { of the population that can most benefit from intense chronic disease manage- } \\
\text { ment is managed by } 1 \text { registered nurse for every } 200 \text { patients. For the remainder of the care-managed patients, } \\
\text { the assumption is that each registered nurse manages } 280 \text { patients. }\end{array}$} \\
\hline
\end{tabular}


Financial Incentive Models Within Fee-for-Service Several innovations in reimbursement designed to reward continuous quality improvement can be provided to complement the existing fee-for-service system. These innovations include bonuses for investing in quality improvement initiatives and financial rewards based upon physician performance. The bonus models have been pioneered by associations of employers, such as the Bridges to Excellence ${ }^{26}$ program and the Leapfrog Group. ${ }^{27}$ Several insurers also offer bonuses based on outcomes and patient satisfaction.

Physician Incentives. The adoption of key elements of the New Model could be facilitated by providing incentive payments to physicians to implement such features as EHRs and chronic disease management. Programs of this type have been created by employer associations and health plans across the country in an effort to improve quality. Some of these financial incentive models include the following ${ }^{28}$ :

- Quality bonuses: payments are made to participating physicians to reward specific investments in systems, or programs designed to increase the quality of medical care, such as care management, patient education, or EHRs.

- Compensation at risk: a portion of the physician's income is withheld by the payer and then paid to physicians at year's end based on adherence to quality improvement steps.

- Performance-based fee schedules: fee schedules for reimbursement of services are adjusted based on the physician's adoption of quality improvement initiatives, as reflected in patient outcomes data and patient satisfaction surveys.

- Quality grants: physicians are encouraged to apply for grants offered by health plans or employers for systems or programs designed to improve the quality of care.

- Reimbursement for care planning: care planning or management for patients with chronic illness becomes a reimbursable service for physicians.

Estimated Physician Compensation Under Bonus Model. In this analysis, the impact of alternative bonus programs on physician compensation is estimated cardiac conditions. using the Bridges to Excellence program as a benchmark. The Bridges to Excellence program provides the following awards for physicians receiving minimum scores on practice features:

- Physician office link: enables physicians to earn up to $\$ 50$ per patient, up to a cap of $\$ 20,000$ based upon implementation of specific processes for improving quality, including (1) a $\$ 25$ payment per patient for investing in an EHR system for patients, which is assumed to phase out over 3 years as the EHR becomes established $_{i}(2)$ a $\$ 5$ payment per patient for establishing patient education programs; and (3) a \$10 annual payment per patient per year for care management.

- Diabetes care link: enables physicians with high performance in diabetes care to earn $\$ 80$ per diabetic patient per year.

- Cardiac care link: enables physicians with high performance in treatment of cardiac care patients to receive up to $\$ 160$ per patient per year

Physicians who qualify for all 5 bonuses could add up to $\$ 44,200$ of total compensation per physician (Table 12). This estimate assumes that the costs

\section{Table 12. Change in Physician Compensation Under New Model With Bonus Incentive Programs}

\begin{tabular}{|c|c|c|}
\hline Payment Category & $\begin{array}{l}\text { With } 18 \% \text { Reduction } \\
\text { in Hours Worked, } \$\end{array}$ & $\begin{array}{l}\text { With Current } \\
\text { Work Hours, }{ }^{*} \$\end{array}$ \\
\hline \multicolumn{3}{|l|}{ Current average compensation } \\
\hline Mean compensation per FTE physician ${ }^{\dagger}$ & 167,500 & 167,500 \\
\hline \multicolumn{3}{|l|}{$\begin{array}{l}\text { Changes in physician compensation per } \\
\text { physician }\end{array}$} \\
\hline $\begin{array}{l}\text { New model under current FFS system } \\
\text { (taken from previous microanalysis) }\end{array}$ & $(20,900)$ & 42,800 \\
\hline \multicolumn{3}{|l|}{ Physician office link potential bonus ${ }^{\ddagger}$} \\
\hline $\begin{array}{l}\text { With EHR bonus ( } \$ 25 \text { per patient } \\
\text { per year) }\end{array}$ & $0-12,500$ & $0-12,500$ \\
\hline $\begin{array}{l}\text { Patient education bonus ( } \$ 5 \text { per } \\
\text { patient per year) }\end{array}$ & $0-2,500$ & $0-2,500$ \\
\hline $\begin{array}{l}\text { With care management bonus } \\
(\$ 10 \text { per patient per year) }\end{array}$ & $0-5,000$ & $0-5,000$ \\
\hline \multicolumn{3}{|l|}{ Diabetes care link potential bonus $\S$} \\
\hline Diabetes care link & $0-11,400$ & $0-13,000$ \\
\hline \multicolumn{3}{|l|}{ Cardiac care link potential bonus" } \\
\hline Cardiac care link & $0-9,750$ & $0-11,200$ \\
\hline Total change in compensation & $(20,900)-20,250$ & $42,800-87,000$ \\
\hline \multicolumn{3}{|l|}{ Total compensation under policy } \\
\hline Total net physician compensation & $146,600-187,750$ & $210,300-254,500$ \\
\hline
\end{tabular}

Source: Lewin Group estimates using illustrated assumptions. ${ }^{13}$

FTE = full-time-equivalent; FFS = fee-for-service; EHR = electronic health record

Note: numbers in parentheses indicate loss.

* Assumes physicians use savings in time worked to increase the number of patients served.

† Assumes all patients are enrolled in participating health plans. Assumes average panel of about 2,030 patients per FTE physician.

‡ Bonus amounts capped at $\$ 20,000$ per physician.

$\S$ Bonus of up to $\$ 80$ per diabetes patient for high scores on diabetes care. Assumes $7 \%$ of patients have diabetes. II Bonus of up to $\$ 160$ per cardiac patient for high scores in providing cardiac care. Assumes $3 \%$ of patients have 
of achieving these high-quality services are embedded in the cost of adopting the New Model as discussed above. It also assumes that the physician earns the maximum bonus under the physician office link program (ie, \$20,000), that $7 \%$ of the physician's patient panel has diabetes, and that about $3 \%$ have qualifying cardiac conditions.

\section{Mixed Reimbursement Model}

An alternative approach to funding the New Model is to rely upon a mix of reimbursement methods. Under such an approach, fee-for-service reimbursement would remain as the primary form of reimbursement, but physicians would receive a fixed annual payment amount for each patient in their panel to fund the cost of adopting the New Model. The per-patient fee is designed to recover the costs associated with providing the higher level of care and service under the New Model. The program could also include specific bonuses for high scores in providing primary care for patients with chronic diseases, such as diabetes and heart disease, plus an additional bonus based on other performance measures.

The reimbursement provisions that were adopted for this scenario are described below:

- Fee-for-services reimbursement: Under the mixed model of reimbursement, physicians would continue to obtain payments for individual services on a fee-for-service basis as they do under current practices.

- New Model per-patient fee: Under the mixed model of reimbursement, physicians would receive an annual payment per patient to implement the features of the New Model, ie, New Model per-patient fee. It is assumed that physicians are paid $\$ 10$ per patient per year to provide services consistent with the New Model, resulting in net revenues of $\$ 20,300$ for an average physician (assumes a 2,030-patient panel), which almost covers the reduction in net compensation for physicians who choose not to increase their patient volume.

- Chronic care bonus: It is assumed that physicians receive bonuses for providing a high level of care and chronic disease management for patients with selected chronic conditions. The model developed under the Bridges to Excellence initiative discussed above is used as an example. This reimbursement provision include the 2 following links: (1) the diabetes care link program, which provides payments of up to $\$ 80$ per year per diabetic patient depending upon performance scores in chronic disease management for diabetic patients; and (2) the cardiac care link program, which provides up to $\$ 160$ per cardiac patient per year for physicians scoring high on chronic disease management indicators and processes for such patients.
- Overall performance bonus: Finally, physicians would be eligible for bonuses based upon various measures of overall performance. These measures would include patient satisfaction surveys, HEDIS (Health Plan Employer Data and Information Set) measures, use of generic prescriptions, and other measures negotiated with participating physicians. It is assumed that the maximum bonus would be $\$ 20,000$ per physician per year. Some health plans already have bonus systems with comparable maximum bonus potential.

Under this scenario, average physician compensation under the New Model for physicians with a reduced work week would be about the same as under current practices, even if they do not qualify for a bonus (Table 13), because physicians are provided with the New Model per-patient fee, which roughly covers the cost of implementing the New Model.

Physician compensation could increase substantially for physicians who use productivity increases under the New Model to provide care to more patients while working the same number of hours. Compensation would increase by between $\$ 66,100$ and $\$ 110,300$ depending upon the bonuses earned under the system for physicians who continue to work the same number of hours.

The United Kingdom (UK) offers an example of a health care system that has begun to implement some of these innovative reimbursement changes to enhance primary care. General practitioners in the UK have traditionally been compensated under a mixed reimbursement model including capitation (40\%), salary (30\%), capital and information technology (15\%), and fee-forservice, including quality-based incentives (15\%). ${ }^{29} \mathrm{~A}$ new general practitioner reimbursement contract was introduced in April 2004, which will increase primary care expenditures by $£ 1.9$ billion per year (an increase of $33 \%$ over 3 years). A quality incentive system, involving 146 indicators across 7 areas of practice, is central to this contract.

\section{Compensation Under Alternative Business Models for the New Model}

Figure 1 illustrates estimates of average family physician compensation under alternative business models for the New Model. For physicians who continue to work the same number of hours, it is expected that average compensation per physician would increase from approximately $\$ 167,500$ under current practices to about $\$ 210,300$ under the New Model (assuming no change in existing reimbursement systems). This increase in compensation and income is approximately $26 \%$. If all the described changes in reimbursement were implemented, the total average compensation would rise by $61 \%$ to an estimated $\$ 277,800$, as shown in Figure 1. 
The New Model and Systemwide Health Care Spending

The New Model must be evaluated in terms of its implications for health care spending throughout the system. True integration of care, improvements in patient safety, and monitoring of chronic care have the potential to reduce spending for hospital care and physician specialist services. Moreover, it is widely documented that patient care costs are reduced when patients obtain their primary care through primary care physicians rather than other specialists. Thus, the New Model is likely to result in savings to employers and health plans. Increasing the emphasis on primary care could produce large dividends throughout the health care system, only part of which would result in increased compensation to the primary care physicians that would make these savings possible.

Relationship Between Primary Care and Systemwide Health Care Spending. The potential for savings

\section{Table 13. Change in Compensation per Physician Under New Model} With Mixed Reimbursement Model

\begin{tabular}{|c|c|c|}
\hline Payment Category & $\begin{array}{l}\text { With } 18 \% \text { Reduction } \\
\text { in Hours Worked, } \$\end{array}$ & $\begin{array}{l}\text { With Current } \\
\text { Work Hours, \$* }\end{array}$ \\
\hline \multicolumn{3}{|l|}{ Current average compensation } \\
\hline Mean compensation per FTE physician ${ }^{\dagger}$ & 167,500 & 167,500 \\
\hline \multicolumn{3}{|l|}{$\begin{array}{l}\text { Changes in physician compensation per } \\
\text { physician }\end{array}$} \\
\hline $\begin{array}{l}\text { New Model under current fee-for-service } \\
\text { model (taken from microanalysis) }\end{array}$ & $(20,900)$ & 42,800 \\
\hline \multicolumn{3}{|l|}{ Annual New Model fee per patient ${ }^{\ddagger}$} \\
\hline $\begin{array}{l}\text { New Model fee per patient ( } \$ 10 \text { per } \\
\text { patient per year) }\end{array}$ & 20,300 & 23,300 \\
\hline \multicolumn{3}{|l|}{ Diabetes care link potential bonus ${ }^{\S}$} \\
\hline Diabetes care link bonus & $0-11,400$ & $0-13,000$ \\
\hline \multicolumn{3}{|l|}{ Cardiac care link potential bonus" } \\
\hline Cardiac care link bonus & $0-9,750$ & $0-11,200$ \\
\hline \multicolumn{3}{|l|}{ Annual performance reward } \\
\hline $\begin{array}{l}\text { Performance award scored on: } \\
\text { Use of generic drugs } \\
\text { Patient satisfaction survey } \\
\text { HEDIS performance measures }\end{array}$ & $0-20,000$ & $0-20,000$ \\
\hline Total change in compensation & $(600)-40,550$ & $66,100-110,300$ \\
\hline \multicolumn{3}{|l|}{ Total compensation under policy } \\
\hline Total net physician compensation§ & $166,900-208,050$ & $235,500-277,800$ \\
\hline \multicolumn{3}{|c|}{ Source: Lewin Group estimates using illustrated assumptions. ${ }^{13}$} \\
\hline \multicolumn{3}{|c|}{ FTE = full-time-equivalent; HEDIS = Health Plan Employer Data and Information Set. } \\
\hline \multicolumn{3}{|l|}{ Note: numbers in parentheses indicate loss. } \\
\hline \multicolumn{3}{|c|}{$\begin{array}{l}\text { *Assumes physicians use savings in time worked to increase patient volume to maintain total hours worked per week. } \\
\text { † Assumes all patients are enrolled in participating health plans. Assumes average panel of about } 2,030 \text { patients } \\
\text { per FTE physician. }\end{array}$} \\
\hline \multicolumn{3}{|c|}{$\begin{array}{l}\text { ₹ Annual fee based upon the net cost of implementing the New Model (estimated net cost of } \$ 18,123 \text { at current } \\
\text { patient volume, rounded to } \$ 10 \text { per patient). }\end{array}$} \\
\hline \multicolumn{3}{|c|}{$\begin{array}{l}\S \text { Bonus of up to } \$ 80 \text { per diabetes patient for high scores in providing diabetes care. Assumes } 7 \% \text { of patients } \\
\text { are diabetic. }\end{array}$} \\
\hline \multicolumn{3}{|c|}{$\begin{array}{l}\text { II Bonus of up to } \$ 160 \text { per cardiac patient for high scores in providing cardiac care. Assumes } 3 \% \text { of patients have } \\
\text { cardiac conditions. }\end{array}$} \\
\hline I Annual bonus amount based upon performance & ators up to $\$ 20,000$ per physiciar & \\
\hline
\end{tabular}

from increased emphasis on primary care is illustrated in a study ${ }^{30}$ comparing health care costs across other industrialized nations. There is a strong correlation between a nation's emphasis on primary care, as measured by a composite primary care score, and per capita spending for health care services. The primary care score was an average of scores on 11 different features of primary care, 5 of which were characteristics of the health care system in general and 6 of which reflected the extent to which primary care practice explicitly attempts to achieve a higher level of performance for the specific features that define primary care plus 2 additional related features. The United States ranked lowest across the 11 nations included in the study according to the composite primary care score, yet it has per capita health care costs that are nearly twice that of any other nation. The United States also ranked lowest in patient satisfaction across these countries. The implication is that increased emphasis on primary care reduces overall health care costs and increases patient satisfaction.

Another study ${ }^{31}$ shows that patients who have a primary care physician as their primary source of care have lower health care expenses than do those who use a non-primary-care physician specialist as their primary source. This analysis is based upon the 1998 National Medical Expenditures Survey, which shows that about $88 \%$ of the population reports they have a primary care physician as their usual source of care, while $12 \%$ had a non-primary-care physician specialist as their primary source of care. After adjusting for differences in demographic and health status characteristics for these populations, the data show that per capita health care spending for all health care services was about $50 \%$ higher for patients using a specialist other than a primary care physician as their primary source of care. Average costs adjusted to 2004 dollars were about $\$ 340$ per person per month among those using primary care physicians compared with $\$ 506$ per person per month for patients using other specialists as their primary source of care. These data also show lower mor- 


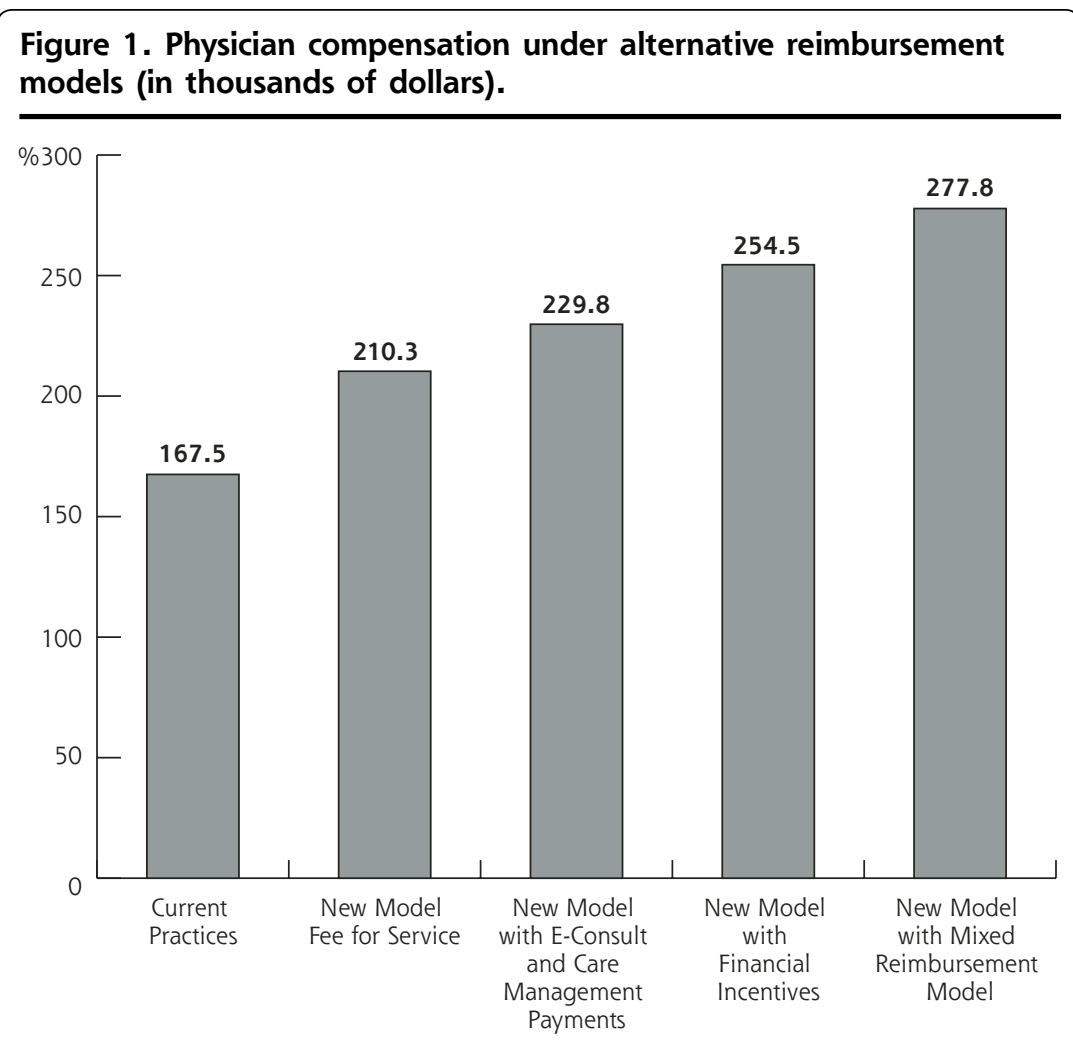

Source: Lewin Group estimates. ${ }^{13}$

Note: Assumes physicians use savings in time worked to increase patient volume to maintain total hours worked per week. tality levels for those using primary care physicians, even after standardizing for demographic and health status differences.

Nationwide, spending for health care services is estimated to average about $\$ 360$ per person per month in 2004 (excludes insurer administration, public health, and research and construction). ${ }^{32}$ Of this, about $18 \%$ is for services provided by primary care physicians (Figure 2). Other specialists account for about $23.1 \%$ of health care spending while hospitals account for about $37.9 \%$ of spending. Other health care services, including prescription drugs, account for about $21 \%$ of health care spending.

Potential Savings From Expanded Use of Primary Care. These data suggest that increased use of primary care physicians resulted in reduced hospitalizations and reduced spending for other non-primary-care specialist services with improvements in important measures, eg, lower

\section{Figure 2. Changes in health care spending according to service type with expanded primary care, 2004.}

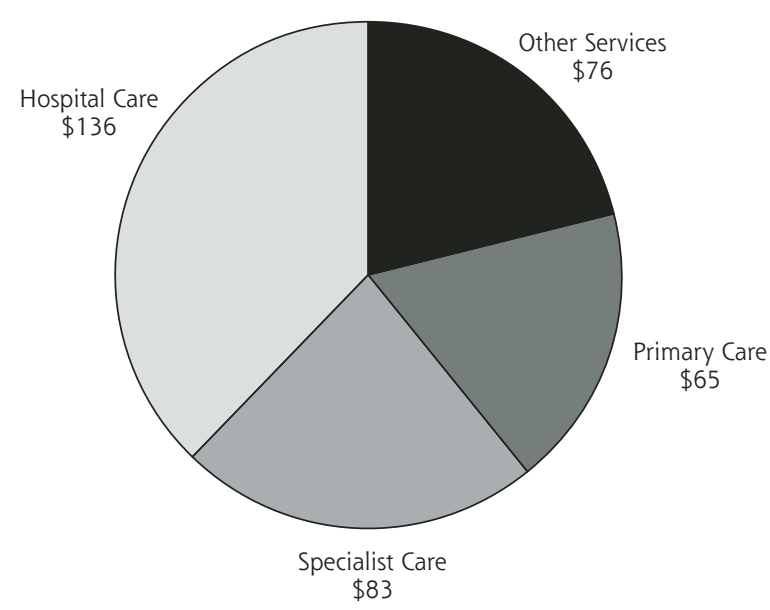

Per Capita Spending $=\$ 360$ PMPM

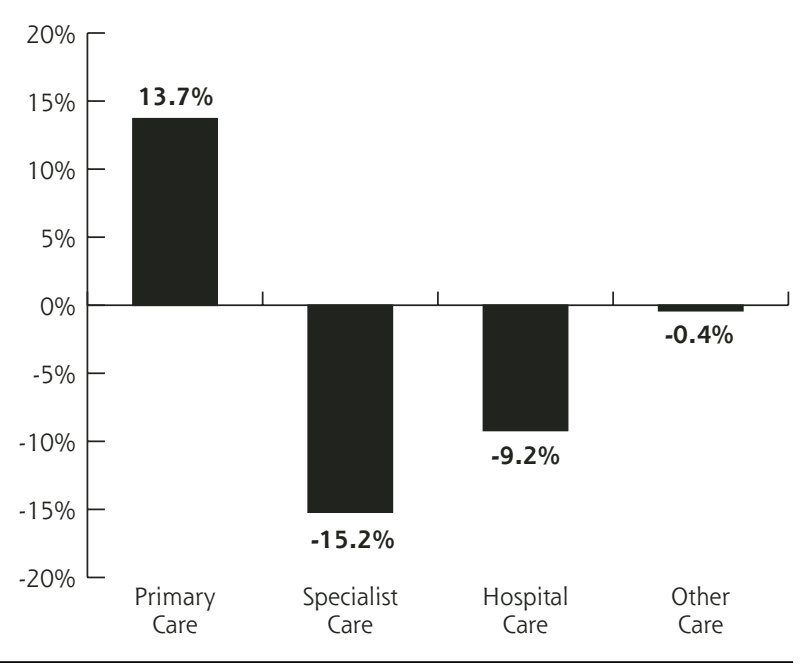

Source: Lewin Group estimates. ${ }^{13}$

PMPM = per member per month.

Notes: Estimates of health spending are for privately insured persons excluding dental coverage. Distribution estimated by the Lewin Group using the Medical Expenditures Panel Survey data (MEPS)

Changes in health spending assume an increase in primary care physician utilization in proportion to the number of persons using a primary care provider as their primary source of care. Assumes a corresponding reduction in specialist utilization at the higher levels of reimbursement received by specialists. Assumes reduction in hospital and other care corresponding to the estimated savings in health care of $\$ 67$ billion. 
mortality rates. This outcome is largely because primary care physicians typically have lower charges than other specialists and typically use fewer expensive diagnostic services. ${ }^{33}$ The implication is that if all patients were to adopt a primary care physician as their primary source of care, average total health care spending would decline by about $\$ 20$ per person per month (ie, savings averaged across the total population). In addition, this savings is approximately $5.6 \%$ nationwide. This increase in demand for primary care services could be accommodated by the increased capacity of family physicians under the New Model.

Shifting to primary care physicians as the primary source of care would actually increase spending for primary care physicians by about $\$ 8.64$ per person per month, reflecting increased use of services provided by these physicians. Other specialist costs, however, would decline by about $\$ 12.60$ per person per month, and hospital costs would decline by an additional $\$ 12.50$ per person per month. There also would be savings of about $\$ 3.40$ per person per month for other services, including prescription drugs (Figure 2). Based upon these data, it is estimated that the total net reduction in health care spending resulting from the shift to primary care could be about $\$ 67$ billion nationally if everyone used a primary care physician as their usual source of care.

Studies have shown that there is a negative relationship between the level of health care spending and the quality of care provided. A recent study by Baicker and Chandra $^{34}$ indicates that geographic areas with a greater share of primary care physicians consumed less care and had better health outcomes as measured according to 24 quality measures developed by the Medicare Quality Improvement Organization. The authors write that "states with higher Medicare spending have lower-quality care. This negative relationship may be driven by the use of intensive, costly care that crowds out the use of more effective care." These results are consistent with previous studies indicating that primary care reduces costs overall and improves outcomes. ${ }^{35}$

Quality and Mortality Indicators. Health care systems that are based on primary care have been shown to have higher quality outcomes, as measured by population-level measures of health, ${ }^{30,35-38}$ and similar quality of person-level health status for patients with chronic illnesses ${ }^{33,39,40}$ when compared with systems of care that are more specialist-dominated. Other studies also indicate a positive relation between primary care and mortality rates. For example, the Franks study ${ }^{31}$ discussed above indicates that patients with primary care physicians as their primary source of care have lower 5 -year mortality rates $(6.2 \%)$ than do patients who use a subspecialist as their primary source of care $(8.1 \%)$. In addition, a recent study by Shi et $\mathrm{al}^{41}$ indicates that access to primary care is associated with reduced mortality and that primary care can potentially offset the negative health effects of low income on mortality.

Systemwide Savings Associated with Primary Care, New Model Practice, and Alternative Reimbursement Models. The available research shows that primary care physicians have the capacity to reduce health care spending for all payers including employers, individuals, and governments. As discussed above, the evidence suggests that if those who now use a subspecialist as their primary source of care were to shift to primary care physicians, national health care spending would drop by about $\$ 67$ billion in 2004 .

This estimate assumes an increase in primary care physician revenue of about $13.7 \%$ as the population shifts to primary care physicians; it implies an increase in primary care physician revenues of about $\$ 55,500$ per year. The savings to payers from adopting the primary care model, however, would average about $\$ 241,000$ per primary care physician. This figure is calculated as total savings from using primary care physicians as the primary source of care for all patients $\$ 67$ billion as estimated above) divided by the total number of primary care physicians $(277,748)$, including physicians in family medicine $(72,360)$, general practice $(13,694)$, general internists $(130,581)$, and pediatricians $(61,113){ }^{42}$ This calculation reflects an estimated reduction in specialty care services of about $15.2 \%$ and a reduction in hospital spending of about $9.2 \%$.

\section{DISCUSSION}

The accuracy of any economic or financial prediction model is dependent on the accuracy of the assumptions contained in the model. The models described in this report contain a number of assumptions. These assumptions were based on information derived from the published medical literature, existing practice management databases, and discussions with experienced physicians and other content experts. There was less literaturebased information available for the microeconomic model, and this analysis was more heavily reliant on expert judgment. The projections of the financial impact of the New Model are based on the best information available; the accuracy of the projections must ultimately be tested in a live demonstration project. The macroeconomic model was more heavily based on data from the published literature, and it also used assumptions based on some reimbursement methods that are currently being utilized on a limited basis. The projection of major cost savings to the health care system based on a wider use of primary care physicians is consistent with the findings of studies of other countries with stronger primary health care delivery. ${ }^{30,35-38}$ The analysis assumes 
that widespread implementation of the New Model of care would encourage most patients to utilize primary care physicians, ultimately decreasing the overall cost of health care. It does not assume financial inducements to patients to increase primary care physician utilization; such incentives would likely further increase the magnitude of health care system savings. The incremental costs of a transition to the New Model of care are considerable, but these costs can be offset by increased revenues attributable to improved efficiencies of care and ultimately by new methods of reimbursement that recognize enhanced quality and value of care. Implementation of the New Model should result in a win-win outcome for patients, payers, and family physicians alike.

\section{CONCLUSIONS}

The task force draws the following conclusions from its deliberations and analyses:

- The United States has the opportunity to enhance the value of the health care system by strengthening primary care expenditures.

- The New Model should enhance health care, while propelling the US system toward improved performance and results that are satisfying to patients, health care professionals, purchasers, and payers.

- In the current payment system, the New Model should result in increased volume of services and quality of care provided by family physicians.

- The net financial impact of the New Model could be at minimum a $5 \%$ reduction in health care expenditures.

- Family physicians could use the New Model efficiency to increase compensation or to reduce work time.

- Alternative reimbursement methods that are compatible with the New Model would allow family physicians to share in the health care cost savings achieved as a result of effective and efficient delivery of care.

- Transition costs are a formidable barrier to transforming frontline health care and require immediate attention through additional payments in the current system or moving to more innovative models of payment directed toward value generation.

The New Model needs to be implemented now. Given the recognized need for improvements in the US health care system in the areas of quality, safety, access, and costs, there is no reason to delay.

\section{RECOMMENDATIONS}

Based on these conclusions, the task force makes the following recommendations:

Recommendation 6.1. A national demonstration project should be launched immediately, involving 10 to 20 family medicine practices of varying sizes, locations, and patient populations, to implement fully all elements of New Model. This 24- to 36-month project should be an "in vivo" exercise focused on demonstrating proof of concept. A careful multimethod evaluation program should be imbedded in the project to determine empirically the business and medical performance characteristics of the New Model.

Recommendation 6.2. One or more business entities should be created to facilitate the implementation of the New Model by providing products and services necessary for a turnkey implementation, as well as consultation on selective components of the model. This assistance organization should be launched in tandem with the demonstration project.

Recommendation 6.3. Federal and private sector leadership is needed at various levels to assure a coherent and sustained movement toward the New Model. This movement should include support for (1) experimental payment strategies, such as blended payment including fees per patient, fees for service, and incentives for performance; and (2) standardization of data across health care settings in support of the New Model and the rest of the health care system.

To read or post commentaries in response to this article, see it online at http://www.annfammed.org/cgi/content/full/2/suppl_3/S1.

Key words: Family practice; primary health care; family medicine; medical informatics; patient-centered care; practice management; quality of health care; health care costs; reimbursement, incentive; economics

Funding support: The Future of Family Medicine project was supported by the following family medicine organizations: American Academy of Family Physicians (AAFP), American Academy of Family Physicians Foundation (AAFPF), American Board of Family Practice (ABFP), Association of Departments of Family Medicine (ADFM), Association of Family Medicine Residency Directors (AFMRD), North American Primary Care Research Group (NAPCRG), and Society of Teachers of Family Medicine (STFM). Major support was contributed by Eli Lilly Foundation, Pharmacia, Pharmacia Foundation, Pfizer, Pfizer Foundation, and the Robert Wood Johnson Foundation. In addition, generous support was obtained from the Health Resources and Services Administration, Schering-Plough Corporation, and Wyeth Pharmaceuticals.

Acknowledgments: Special thanks are extended to members of the Family Medicine Working Party and the American Academy of Family Physicians Board of Directors, who provided guidance and direction to development of this report.

Task Force 6: Stephen J. Spann, MD, MBA, Chair, Baylor College of Medicine, Houston, Tex; Don Cauthen, MD, Scott and White Clinic, Temple, Tex; William L. Boddie, MD, FACPE, Kaiser Permanente, Atlanta, Ga; Robert L. Crocker, MD, Wellpoint Health Networks, Westlake Village, Calif; Raymond J. Fabius, MD, FACPE, Global Medical Leader at GE I Medicalogic, New Town Square, Pa; Michael Fleming, MD, The Family Doctors, Shreveport, La; Larry A. Green, MD, Robert Graham Center: Policy Studies in Family Practice \& Primary Care, Washington, DC, and Department of Family Medicine, University of Colorado, Denver, Colo; 
Rhonda Medows, MD, Tallahassee, Fla; Richard G. Roberts, MD, JD, Department of Family Medicine, University of Wisconsin, Madison, Wisc; William D. Rogers, MD, FACEP, Centers for Medicare and Medicaid Services, Alexandria, Va; Kirsten Sloan, AARP Federal Affairs, Washington, DC; and Norman B. Kahn, Jr, MD, Task Force Advisor, American Academy of Family Physicians, Leawood, Kan.

Task Force 6 Executive Editorial Team: Kent Moore, MPA, American Academy of Family Physicians, Leawood, Kan; Jan Carter, MBA, American Academy of Family Physicians, Leawood, Kan; Marilyn A. McMillen, MBA, American Academy of Family Physicians, Leawood, Kan.

Project Leadership Committee: James C. Martin, MD, Project Leadership Committee Chair; Robert F. Avant, MD; Marjorie A. Bowman, MD, MPA; John R. Bucholtz, DO; John C. Dickinson, MD; Kenneth L. Evans, MD; Larry A. Green, MD; Douglas E. Henley, MD; Warren A. Jones, MD; Samuel C. Matheny, MD, MPH; Janice E. Nevin, MD, MPH; Sandra L. Panther, CFRE; James C. Puffer, MD; Richard G. Roberts, MD, JD; Denise V. Rodgers, MD; Roger A. Sherwood, CAE; Kurt C. Stange, MD, PhD; Cynthia W. Weber, MA.

Future of Family Medicine Research Advisory Committee: John R. Bucholtz, DO; John C. Dickinson, MD; Larry A. Green, MD; Warren A. Jones, MD; James C. Martin, MD; Richard G. Roberts, MD, JD; Kurt C. Stange, MD, PhD.

Future of Family Medicine Project Staff: Norman B. Kahn, Jr, MD, FFM Staff Executive; Sarah Thomas, Assistant Staff Executive; Marilyn A. McMillen, MBA, Project Manager; Dorothy Young, FFM Administrative Assistant; Ruth Coram, FFM Staff Assistant; Nina Carnoali, FFM Staff Assistant; Toni Lapp, Associate Editor. Special thanks to David Wright in preparation of this report.

Task Force 6 Reactor Panel: American Association of Retired Persons (William Novelli, CEO); American College of Osteopathic Family Physicians (R. Greg Maul, DO, President); American College of Physicians (John Tooker, MD, EVP); Donnie Batie, MD; James D. Bentley, PhD; Norman Chenven, MD; David Ellington, MD; Thomas Felger, MD; Paul Ginsburg; Steve Green, MD; Lori Heim, MD; Emily Hill, PA-C; Dennis Horrigan, MD; Charles B. Inlander; James Kennedy, MD; Chuck Kilo, MD, MPH; Allan Korn, MD; Magnus Lundberg; Steven Masley, MD; Arnold Milstein, MD; Mark Needham, MD, MBA; Lee Newcomer, MD; Ed O'Neil, PhD; Christine Petty, MD; John Sattenspiel, MD; Barbara Starfield, PhD; Richard Zachrich, MD.

\section{References}

1. Future of Family Medicine Project Leadership Committee. The future of family medicine: a collaborative project of the family medicine community. Ann Fam Med. 2004;2(Suppl 1):S3-S32.

2. Green LA, Graham R, Bagley B, et al. Task Force 1. Report of the Task Force on Patient Expectations, Core Values, Reintegration, and the New Model of Family Medicine. Ann Fam Med. 2004;2:S33-S50. Available at: http://www.annfammed.org/cgi/content/full/2/suppl_1/S33.

3. Bucholtz JR, Matheny SC, Pugno PA, et al. Task Force Report 2. Report of the Task Force on Medical Education. Ann Fam Med. 2004;2:S51-S64. Available at: http://www.annfammed.org/cgi/content/full/2/suppl_1/S51.

4. Jones WA, Avant RF, Davis N, Saultz J, Lyons P. Task Force Report 3 Report of the Task Force on Continuous Personal, Professional, and Practice Development in Family Medicine. Ann Fam Med. 2004;2: S65-S74. Available at: http://www.annfammed.org/cgi/content/full/2/ suppl_1/S65.
5. Dickinson JC, Evans KL, Carter J, Burke K. Task Force Report 4. Report of the Task Force on Marketing and Communications. Ann Fam Med. 2004;2: S75-S87. Available at: http://www.annfammed.org/cgi/ content/full/2/suppl_1/S75.

6. Roberts RG, Snape PS, Burke K. Task Force Report 5. Report of the Task Force on Family Medicine's Role in Shaping the Future Health Care Delivery System. Ann Fam Med. 2004;2:S88-S99. Available at: http://www.annfammed.org/cgi/content/full/2/suppl_1/S88.

7. World Health Organization. The World health report, 2000. Health systems: improving performance. Geneva: World Health Organization. 2000. Available at: http://www.who.int/whr/2000/en/.

8. Institute of Medicine. Committee on Quality of Health Care in America. Crossing the Quality Chasm: A New Health System for the 21st Century. Washington DC: National Academy Press; 2001.

9. 2004 New Model Focus Group Report. Available at: http://www. futurefamilymed.org.

10. O'Hare CD, Corlett J. The outcomes of open-access scheduling. Fam Pract Manag. 2004;22:35-38.

11. Scherger JE. Communicating with your patients online. Fam Pract Manag. 2004;11:93-94.

12. Edsall RL. Are electronic records catching on? Fam Pract Manag. 2004;11:13.

13. The Lewin Group. Financial model for sustaining family medicine and primary care practices. July 15, 2004. Available at: http://www. futurefamilymed.org.

14. AppointmentQuest Web page. Available at: http://www.appointmentquest.com/business/pricing. Accessed September 1, 2004.

15. Barlow S, Johnson J, Steck J. The economic effect of implementing an EMR in an outpatient clinical setting. Health Info Manag. 2004; 18:46-51.

16. Wang SJ, Middleton $B$, et al. A cost-benefit analysis of electronic medical records in primary care. Am J Med. 2003;114:397-403.

17. Houck S, Kilo C, Scott JC. Improving patient care. Group visits. Fam Pract Manag. 2003;10:66-68.

18. American College of Physicians Medical Service Committee. The changing face of ambulatory medicine - reimbursing physicians for computer-based care. Policy Paper. American College of Physicians Medical Service Committee, March 2003.

19. Donaldson MS, Yordy KD, Lohr KN, Vanselow NA, eds, for the Institute of Medicine Committee on the Future of Primary Care. Primary Care. America's Health in a New Era. Washington, DC: National Academy Press; 1996.

20. Sintchenko V, Coiera E, Iredell JR, Gilbert GL. Comparative impact of guidelines, clinical data, and decision support on prescribing decisions: an interactive web experiment with simulated cases. J Am Med Inform Assoc. 2004;11:71-77.

21. American Academy of Family Physicians, 2003 Practice Profile Survey, I. Leawood, Kan: American Academy of Family Physicians; 2003.

22. Wassenaar JD, Thran SL. Physician Socioeconomic Statistics, 2000-2002 Edition: Profiles for Detailed Specialties, States, and Practice Arrangements. Chicago, III: American Medical Association, Center for Health Policy Research; 2001.

23. Direct Research, LLC for the Medicare Payment Advisory Commission. Medicare physician payment rates compared to rates paid by the average private insurer, 1999-2001. August 27, 2003. Available at: http://www.medpac.gov1.

24. Norton, S. Recent trends in Medicaid physician fees, 1993-1998. Washington, DC: New Hampshire Office of Planning and Research. Urban Institute; 1999. Paper No. 99-12.

25. Medical Group Management Association. Cost Survey: 2003 Report Based on 2002 Data. Englewood, Colo: Medical Group Management Association; 2004. 
26. Bridges to Excellence: Rewarding Quality Across the Healthcare System. Web site. Available at: http://www.bridgestoexcellence.org/bte/.

27. The Leapfrog Group for Patient Safety. Rewarding Higher Standards. Web site. Available at: http://www.leapfroggroup.org/.

28. American Medical Association Private Sector Advocacy Group. How physician incentives are used to impact medical practice. 2003. Available at: http://www.ama-assn.org/ama1/pub/upload/mm/368/ incentivesbook/pdf.

29. Smith P, Nick Y. Quality incentives: the case of UK general practitioners. Health Aff (Millwood). 2004;23:112-118.

30. Starfield B. Is primary care essential? Lancet. 1994;344:1129-1133.

31. Franks P, Fiscella K. Primary care physicians and physician specialists as personal physicians. Health care expenditures and mortality experience. J Fam Pract. 1998;47:105-109.

32. American Academy of Family Physicians. The new model of primary care: knowledge bought dearly. Official policy of the American American Academy of Family Physicians. March, 2004. Available at: http://www.aafp.org/PreBuilt/caremanagementpolicy.pdf.

33. Greenfield S, Nelson EC, Zubkoff M, et al. Variations in resource utilization among medical specialties and systems of care. JAMA. 1992:267:1624-1630.

34. Baicker K, Chandra A. Medicare spending, the physician workforce, and the beneficiaries' quality of care. Health Aff (Millwood). 2004;W4:184-197.
35. Starfield B. Primary care and health. A cross-national comparison. JAMA. 1991;266:2268-2271

36. Starfield B. Is US health care really the best in the world? JAMA. 2000;284:483-485.

37. Starfield B. New paradigms for quality in primary care. Br J Gen Pract. 2001;51:303-309.

38. Starfield B, Powe NR, Weiner JR, et al. Costs vs quality in different types of primary care settings. JAMA. 1994;272:1903-1908.

39. Greenfield S, Rogers W, Mangotich M, Carney MF, Tarlov AR Outcomes of patients with hypertension and non-insulin-dependent diabetes mellitus treated by different systems and specialties: Results from the medical outcomes study. JAMA. 1995;274:1436-1444.

40. Rosenblatt RA. Specialists or generalists: on whom should we base the American health care system? JAMA. 1992;267:1665-1666.

41. Shi L, Macinko J, Starfield B, Wulu J, Regan J, Politzer R. The relationship between primary care, income inequality, and mortality in US states, 1980-1995. J Am Board Fam Pract. 2003;16:412-22.

42. Pasko T, Smart DR. Physician Characteristics and Distribution in the US: 2003-2004 Edition, American Medical Association; Survey and Data Resources. Chicago, III: AMA Press; 2003. 